University of Nebraska - Lincoln

DigitalCommons@University of Nebraska - Lincoln

January 2000

\title{
Birth Order, Sibling Investment, and Fertility among Ju/'hoansi (!Kung)
}

Patricia Draper

University of Nebraska, Lincoln, pdraper1@unl.edu

Raymond Hames

University of Nebraska - Lincoln, rhames2@unl.edu

Follow this and additional works at: https://digitalcommons.unl.edu/anthropologyfacpub

Part of the Anthropology Commons

Draper, Patricia and Hames, Raymond, "Birth Order, Sibling Investment, and Fertility among Ju/'hoansi (!Kung)" (2000). Anthropology Faculty Publications. 9.

https://digitalcommons.unl.edu/anthropologyfacpub/9

This Article is brought to you for free and open access by the Anthropology, Department of at DigitalCommons@University of Nebraska - Lincoln. It has been accepted for inclusion in Anthropology Faculty Publications by an authorized administrator of DigitalCommons@University of Nebraska - Lincoln. 
Published in Human Nature 11:2 (2000), pp. 117-156.

Copyright (C) 2000 by Walter de Gruyter, Inc./Springer Verlag. Used by permission.

Submitted May 9, 1999; accepted July 23, 1999.

Correspondence: Patricia Draper, Department of Anthropology, 126 Bessey Hall, University of Nebraska-Lincoln, Lincoln, NE 68588-0368. Email: pdraper1@unl.edu

\title{
Birth Order, Sibling Investment, and Fertility among Ju/'hoansi (!Kung)
}

\author{
Patricia Draper and Raymond Hames \\ University of Nebraska-Lincoln
}

\begin{abstract}
Birth order has been examined over a wide variety of dimensions in the context of modern populations. A consistent message has been that it is better to be born first. The analysis of birth order in this paper is different in several ways from other investigations into birth order effects. First, we examine the effect of birth order in an egalitarian, small-scale, kin-based society, which has not been done before. Second, we use a different outcome measure, fertility, rather than outcome measures of social, psychological, or economic success. We find, third, that being born late in an egalitarian, technologically simple society rather than being born early has a positive outcome on fertility, and fourth, that number of older siblings and sibling set size are even stronger predictors of fertility, especially for males.
\end{abstract}

Keywords: Africa, birth order, demography, fertility, hunter-gatherers, kin selection, siblings

In this paper we report on a study of the relationship between birth order and reproductive fitness among the Ju/'hoansi (also known as Basarwa, San, or !Kung) of Botswana. Our study, focusing on birth order and fertility in a small-scale, traditional society, is unlike the typical social science studies of the social and psychological correlates of birth order in modern society. We review the findings of birth order effects in modern society below, concentrating on social and economic factors since, in our study of Ju/'hoansi, we do not have measures of psychological variables. 
Before reviewing the literature we will state our problem orientation and hypotheses briefly. In general there appears to be a firstborn advantage, particularly as measured by such indicators as educational achievement, income, occupational prestige, eminence, and IQ (Altus 1966; Bayer 1967; Majoribanks 1988, 1989; Taubman and Behrman 1986; Zajonc and Bargh 1980a, $198 \mathrm{ob})$. As will be discussed more fully below, the implication of these studies is that for a variety of reasons, parents invest more time, energy, and resources in the first or second child than they do in children born later. As we are anthropologists who have worked in small-scale, kin-based and technologically simple societies, we knew how profoundly different child rearing in these places is in comparison with western society. In simpler societies, the isolation of the nuclear family, so common in the west, cannot exist. Settlements are small, housing is often rudimentary, privacy as westerners know it is nonexistent. Further, parents of children are in daily interaction with neighbors and kin because essential activities involve regular cooperation between households and between different families. In this context, what could be the meaning of sibling order? Are the findings from complex societies about a firstborn advantage true, but true for a narrow and temporally restricted range of societies? Does being first-born carry the same cachet in other kinds of societies, particularly where people produce their own subsistence and where material differences of wealth are negligible?

We started with two general hypotheses. First, following the received wisdom, we predicted that firstborn Ju/'hoansi will do "better" than their later born sibs because of the frequently reported developmental benefits of being early born. Specifically, we predicted that they would have higher reproductive success than would later born children. (We say more below about our choice of reproductive success as a dependent variable.) Second, following our own hunch, we predicted that firstborn Ju/'hoansi would not be distinguishable from their sibs in terms of reproductive success because of the contrasting type of family, household, and kinship settings found in egalitarian tribal societies compared with those found in modern stratified societies.

\section{Birth Order Research}

In the following section we review findings from the social science literature on the correlates of birth order. We give primary emphasis to the social and economic correlates since, as stated, we lack psychological measures of our subjects. The literature is extensive, and we refer readers to recent reviews that cover the topic more generally (Salmon and Daly 1998; Steelman and Powell 1985). Different kinds of explanations have been offered to account for the firstborn advantage. Biologically oriented explanations stress 
the greater vigor and health of younger parents, particularly mothers, and argue that as successive children are added to the family, the mother's biological reserves are depleted, leading to less desirable intrauterine as well as postnatal influences on the development of later borns (Adair et al. 1983; Horton 1988; Jacobs and Moss 1976; Miller and Huss-Ashmore 1989; ScheperHughes 1992; Scrimshaw 1984).

Evolutionarily oriented scientists have another set of explanations for a firstborn advantage. Evolutionists, looking from the point of view of parents, see that the oldest child in any set of offspring has the highest reproductive value (Daly and Wilson 1987; Trivers 1974). A ten- or fifteenyear-old is more valuable than younger children in terms of promoting its parents' fitness because it has survived childhood illnesses, and it has absorbed various forms of parental investment and training to a greater extent than any younger child (Voland 1998:360-363). An older child can relieve its parents of child minding work, freeing them for economically productive tasks and making it possible for them to conceive additional children with shorter birth spacing (Hames 1988; Turke 1988). Further, the eldest child is closer to an age when its labor and social alignments with nonrelatives can further the interests of the parents. Therefore, when a family faces some kind of adversity, evolutionary theory predicts that parents will make more sacrifices for older children than younger ones (Bugos and McCarthy 1984; Daly and Wilson 1981, 1988).

Aside from the developmental seniority of firstborns, which makes them more valuable, evolutionary theory makes no predictions for generally unfavorable or discriminatory treatment of later born children who are, from an inclusive fitness perspective, as valuable as firstborns. In fact, some have argued, children born late in a woman's reproductive life span are of increasing value to her because her time to replace them approaches zero (Pennington and Harpending 1988). However, speaking more generally of parental treatment of children, where resources permit, for example in a population that is expanding into a new territory and encountering little or no resistance from an aboriginal population, parents are expected to divide their resources equally, at least among sons (Easterlin et al. 1978).

Economic explanations for firstborn advantage point to that fact that in large families later born children are competing for a smaller portion of the family reserves (Davis 1997; Horton 1988). Sociologically and economically oriented studies of birth order have attempted to control for such factors as socioeconomic status, religious group membership, and number of siblings in the quest for sibling order effects (Steelman and Powell 1985). Birth spacing between successive siblings has also been separately analyzed for confounding effects (Powell and Steelman 1993; Zajonc and Bargh 1980b; Zajonc and Markus 1975). For example, a larger number of siblings and shorter birth 
spacing with arguably undesirable health effects on mother and fetus may be more commonly observed among lower socioeconomic groups.

Studies on westernized or modern, literate populations report that firstborns achieve higher success as measured by years of education, occupational prestige, income level, and IQ (Blake 1986, 1989; Galton 1874). Psychologists have not agreed on the intensity or, in some cases, existence of a birth order effect on personality variables (Ernst and Angst 1983; Jefferson et al. 1998; Schooler 1972). Psychological and educational explanations for firstborn advantage, reported in some studies, argue that firstborn children receive the bulk of their early training from adults, not from other children. They are therefore held to a higher standard and have more competent models to emulate. Later born children are reared in an environment where the average age of household members is younger, producing a dilution of educational and cognitive stimulation. The argument is that the average intellectual age in a family is high when there is only one child, but low when there are several children. Overall, firstborns are more likely to emulate their parents, presumably because the force of their parents' personalities and examples is not diminished by the distractions of other children in the family. Furthermore, oldest children are given responsibility for younger children, which accustoms them early to assuming authority and may give them greater opportunity for self-esteem and self-confidence (Zajonc et al. 1979). In contrast, later born children have been reported to be more sociable and popular with peers (Miller and Maruyama 1976). The explanation offered is that children born into families with older sibs must adapt by mastering better interpersonal skills in order to withstand sibling competition.

A child born later in the sibset occupies a different adaptive niche. The later born child has more competition from siblings for parental attention and more individuals, some of whom are children, on whom to model behavior. The findings that firstborns gravitate to professions with firm hierarchies such as the military, medicine, and teaching, and that they aspire to leadership positions in those professions, are often offered as support for the "natural" developmental consequences of being firstborn (Exner and Sutton-Smith 1970; Galton 1874; Schacter 1963). Others have suggested refinements in these models, pointing out that birth spacing, sibship size, gender sequence, family economic resources, and surrogate rearing, among others, can affect the significance of ordinal position for a person's development (Blake 1986, 1989; Koch 1955; Powell and Steelman 1993:379). Several studies on nonwestern subjects have shown that under some circumstances, such as immigration or economic hardship, later born children can do better, for example, in school. In these cases later born children benefit because their older sibs contribute to the family income or because the elder sibs can tutor them in school tasks, whereas immigrant parents have not mastered the new skills sufficiently to help their children in school (Davis et al. 1977; Shavit and Pierce 1991). Other 
comparative and cross-cultural commentaries on the differential treatment by parents according to the birth order of children are found in Rosenblatt and Skoogberg (1974; also see Hrdy 1992).

In a recent study of birth order, Sulloway argues that the position taken by well-known historical figures with regard to important controversies of their time is associated with birth order (Sulloway 1996). Later borns were more likely to rebel against the prevailing orthodoxy and to side with revolutionary theoretical positions, whereas firstborns aligned themselves with the establishment view. This study was stimulated by findings in psychological literature that a child's birth order and sibship size influence a child's choice of developmental niche (Walton 1997; Worthman 1996).

\section{Customs That Dictate Differential Advantage on the Basis of Birth Order}

Aside from the so-called natural developmental advantage of being firstborn, there are institutional practices that can tip the balance of opportunity systematically in favor of the firstborn; the rule of primogeniture is a case in point. In historical societies there are many examples of male preference or preference for firstborn males to become the heir to titles and the bulk of the family estate (Boone 1986, 1988; Duby 1978; Gaulin and Robbins 1991; Hrdy and Judge 1993; Smith et al. 1987). The weight of primogeniture intensifies any developmental advantage that firstborns might come by "naturally, " a point made by Galton more than one hundred years ago (Galton 1874). In more complex, stratified societies with pronounced class or caste divisions, parents who wished to maintain the strength of family holdings in the form of land concentrated the majority of inheritance on the eldest male. The consequences for male heirs have been analyzed in several studies that also report on the reproductive advantages to elder male heirs (Boone 1986; Low 1990, 1991). These sons have more children and better survivorship among children in comparison with their younger siblings. In some cases later born males emigrate or join armies and leave to fight in foreign wars, thereby placing themselves out of reach of census takers and parish recorders of vital information. However, the presumption is that later borns who emigrate endure greater risks and are, overall, less successful economically and reproductively than their favored older sib (Voland 1984, 1990). Economic and gender variables also affect the relationship (Voland 1990).

Under conditions of increasing economic competition from other families, parents in an agrarian or pastoral economy must face the fact that equal division of property can leave each heir with an insufficient inheritance. Under such restraints, unequal inheritance can preserve family holdings intact, maintain the prestige of the family estate, and insure a livelihood to the off- 
spring of at least one child (Low 1993). As competition increases and economic stratification pushes larger numbers of people into poverty, parents apparently discriminate among offspring, often to the disadvantage of later born children. Reports from studies of impoverished populations in the Third World indicate that children of higher birth order suffer in comparison with earlier borns in nutritional status, mortality, and morbidity. The poor condition of later born children is not necessarily the result of conscious intent or deliberate withholding by the parents. Among poor people, as family size increases, the portion to be shared remains the same. Later born children, therefore, grow up in more deprived conditions. Because they are younger, they are more susceptible to permanent damage from disease and to stunting from poor nutrition. Also, younger children are at a competitive disadvantage from older sibs who eat from the same cooking pot. Relative to their younger sibs, older children in poor circumstances are better off (Horton 1986; Scheper-Hughes 1987; Scrimshaw 1984).

These kinds of institutionalized differential treatments of children are found even in relatively simple societies in which technology permits the accumulation or material wealth (Casimir and Rao 1995). Differential inheritance practices favoring firstborns can be found in many of the East African pastoral societies (Borgerhoff Mulder 1992a, 1992b, 1998; Dyson-Hudson and Meekers 1998; Mace 1996; Roth 1995). Here it is common for the oldest son born to each man's co-wife to inherit a larger share of his father's herds. As a result, the older sons marry earlier, are more likely to have polygynous marriages and to father more total offspring than younger children born to the same mother. Preferential treatment and higher social prestige of firstborns, institutionalized as primogeniture, are reported among many agricultural and horticultural peoples (Rosenblatt and Skoogberg 1974), although systematic data on the relationship between birth order and reproductive success in tribal populations are more rare (Borgerhoff Mulder 1998; Hill and Hurtado 1996; Turke 1988).

Among poorer people in stratified systems where there is little or no wealth to be transmitted, birth order may confer no advantage to sons (Dickemann 1979, 1981). Daughters in disadvantaged strata can have better lifetime outcomes relative to sons because poor daughters have a possibility of marrying men of higher social status. The poor brothers, on the other hand, cannot attract a higher status wife and often remain unmarried and with few offspring (Bailey 1988; Cronk 1989, 1991; Draper 1992). We do not know of data regarding birth order of daughters in nonwestern stratified societies and measures of their status or reproductive success vis-a-vis their sisters. The relationship between maternal advantage (expressed in the form of measures of physical health such as body weight) and reproductive consequences for daughters vs. sons has been explored in nonhuman species (Trivers and Willard 1973). 
Although firstborns in modern societies achieve certain economic and social advantages relative to their later born sibs, it is no longer true that firstborns enjoy a reproductive advantage over their sibs. Because of the requirement of monogamy, the availability of contraception, and the entry of women into the formal labor force, the reliable correlation seen elsewhere between wealth, prestige, and large numbers of offspring has been broken (Davis 1997; Kitcher 1985; Perusse 1993; Vining 1986).

In the next sections we turn to a brief description of the $\mathrm{Ju} /$ 'hoan population and the data Draper collected for our study of the correlates of birth order and fertility. First we digress to highlight some differences between the study of birth order in western populations and our study. We believe the significance of these differences will become apparent later when we present our findings.

\section{Characteristics of Western Studies of Birth Order and Socioeconomic Outcomes and Some Embedded Assumptions}

We discuss the comparisons under the headings of population type, choice of dependent variables, assumptions about family structure, and study design. Population type: it is more common for researchers interested in the correlates of birth order to study people in modern rather than traditional, technologically simple societies. Choice of dependent variables: researchers investigate the relationship between the antecedent variable of birth order and various dependent socioeconomic and personality variables, as reviewed previously. They are rarely interested in fertility as a dependent variable. Family structure: modern studies of consequences of birth order are carried out among people who for the most part live or were reared in isolated nuclear family households. However, the possibility that household structure is an important contributor to birth order effects is not examined, nor deemed salient, because of the lack of variability in household organization of the population under study (Whiting 1960).

In the bi-parental nuclear family that is characteristic of modern, urban populations, parents are key to the well-being of children. As parenting roles are rarely shared to any substantial extent with other kin, parental resources of time, energy, attention, and material goods are inevitably affected by the addition of each new child to the family. We suspect that the unoperationalized variable of the independent, nuclear family household intensified birth order effects for people in modern, complex societies. Study design: the studies are usually cross-sectional and use the variable of birth order as a fixed attribute stemming from the subject's experience of his or her family during childhood. The studies are ego-centered and make an implicit assumption (perhaps culturally correct) that the continuation of sibling interdependence into later ages is not worth investigating. This intra-individual or ego-cen- 
tered focus makes sense within the psychological and developmental paradigms. It also makes sense given the truncation of extended family and multigeneration kinship connections in industrial society.

\section{Characteristics of and Assumptions Embedded in the Ju/'hoan Study of Birth Order and Fertility}

Population Type. We look at the variable of birth order in a small-scale, traditional population in which people lived in a subsistence economy rather than in a modern, market economy. Choice of dependent variables: social scientists look at indicators of achievement that make sense in urban, western society. We have no data for Ju/'hoansi that pertain to comparable educational, socioeconomic, or personality variables. As we explain more fully below in the ethnographic section, the Ju/'hoansi adults we studied had never attended school and their wage work had been sporadic over the life course. Most people had no "occupation" in the western sense of the term. All were or had been subsistence producers, making a living by hunting, gathering, and, more recently, raising goats and cattle. We have no measure of psychological characteristics, though if we did it would be hard to establish comparability with psychological assessments of western subjects. Nevertheless, we wanted to know if Ju/'hoansi, like Westerners, reaped some kind of benefit from being born early to their parents. We needed to find some kind of favorable outcome that could be logically linked to the western measures of achievement and socioeconomic success. We hypothesized that being early born would covary with measures of reproductive success.

We mentioned that, with few exceptions, birth order researchers analyzing western data sets have not been interested in possible correlates with fertility (Davis 1997). Some demographically oriented anthropologists working in traditional communities have asked about the connections between fertility and a person's access to kin. (Beckerman et al. 1998; Borgerhoff Mulder 1998; Chagnon 1979a, 1979b, 1982; Draper and Buchanan 1992; Dyson-Hudson and Meekers 1998; Hames 1979, 1987, 1988; Hill 1993; Hill and Hurtado 1996; Mace 1996; Turke 1988). Birth order, in these kinds of studies, is sometimes reported, but it is not a central issue. More commonly anthropologists with demographic interests have looked at the effects of secular change, health interventions, and disease processes on different age cohorts in economically undeveloped, nonwestern populations (Bledsoe and Pison 1994; Greenhalgh 1995; Hammel 1987; Hausman and Wilmsen 1985; Howell 1979; Kaplan 1996; Pennington and Harpending 1988).

Family Structure. In Ju/'hoansi society, people live in small, kin-based villages of twenty to thirty people in which houses are rudimentary and 
closely spaced. This leads to an "open air" and public context of child rearing in which children have regular contact with close kin of all ages (Draper 1973, 1976; Konner 1972, 1976). At the time our subjects were growing up, most Ju/'hoansi lived in monogamous marriages. Although their households could be classified as "nuclear," there was regular close availability of other village members. A child growing up in such a village context would rarely if ever have occupied the niche of eldest child in a western, nuclear family setting. During the day children were more or less in constant company with other children of the village or band (Draper and Cashdan 1988) and therefore would be less likely to develop an outlook or set of goals based on their birth status. For these reasons our second prediction was that early or firstborn birth order, by itself, would not predict a better lifetime outcome as we measured it, by reproductive success. We thought that the findings from the study of western children and the influence of birth order on personality and achievement were partially influenced by the unique attributes of modern, nuclear family life that intensified competition among siblings.

Study Design. As mentioned above, modern studies of birth order often focus on each individual, his or her birth order, and certain personality or sociological variables that are characteristic of that person. Our study of sibling order is also ego-centered in the sense that we collected data on a person's birth order and that same person's "achievements" as measured by fertility. Our study is less ego-centered in that it tracks, for each individual of known birth order, the survivorship of that person's siblings and thus their potential contribution to his or her lifetime reproductive success. In other words, our study was explicitly guided by a knowledge of Ju/'hoan ethnography, household organization, and interdependence among kin over the lifespan. We knew, barring death, that a person in Ju/'hoan society moved through time in a convoy of siblings. ${ }^{1}$ We wondered if the continued coexistence of siblings, considered separately and together with birth order, might affect reproductive success.

The question to which the remaining portion of our paper is addressed is: What are the consequences of birth order in a nonstratified and egalitarian society in which individually owned property of a real or symbolic nature is negligible? Do firstborn children have an advantage for reasons mentioned above even when primogeniture, competition for property, and leadership position are absent? Can other factors of household organization, domestic architecture, and settlement plan reduce the so-called natural advantages that fall to firstborns since children grow up in small villages and camps with continual access to playmates both older and younger than they?

In order to answer the question "Does birth order affect life time success?" we developed an outcome measure based on reproductive success and looked for a relationship between birth order and numbers of children born and 
numbers of children surviving to adulthood. In settling on this measure we were guided not only by evolutionary theory in which fitness is the measure of success but by $\mathrm{Ju} /$ 'hoan attitudes which stress the incontrovertible importance of kin (including but not limited to offspring) in equipping a person for a good life (Draper and Buchanan 1992).

\section{Ethnographic Background}

The Ju/'hoansi have lived primarily by hunting and gathering in northwestern Botswana and eastern Namibia for recent hundreds if not thousands of years (Yellen 1977, 1984). For some decades they have increasingly abandoned a nomadic, foraging life and have settled around places of permanent water as will be described more fully below. When they lived as foragers the $\mathrm{Ju} /$ 'hoansi did not accumulate material property, and status differences among adults were based on personal characteristics (Lee 1979; Marshall 1976). Leadership was very weakly developed and was not inherited. Since they lacked domestic animals, each man and woman had to be able to carry what he or she owned, which discouraged accumulating any but the most essential goods. Ju/'hoansi did not own the land itself, although they observed a rule of inherited right to named territories which an individual inherited bilaterally through the mother and father. Territories were not defended, although it was considered necessary for outsiders to get permission from hereditary insiders before hunting or gathering in an unfamiliar region (Cashdan 1983; Lee 1979:59-60). Although the Ju/'hoansi lacked productive forms of wealth, their intimate knowledge of the bush, the fact that they lived in small groups and at very low population density, plus the fact that they recognized an obligation to share food with their relatives and visitors gave them a viable subsistence and social life (Dunn 1968; Fernandes-Costa et al. 1984; Hansen et al. 1993; Hausman and Wilmsen 1985; Kent and Lee 1992; Nurse and Jenkins 1977; Wehmeyer et al. 1969; Wilmsen 1982). Adapted to periodic moves, people knew that when food failed or was exhausted in one region, the current living group could disband (Marshall 1960). Family groups, separately or in small parties, moved off to different localities where they knew some of their kin and affines were to be found (Marshall 1961).

In this mobile but communal economy, people had a form of wealth in their access to people. The ties that bound people together were primarily those of bilateral kinship and marriage, although Ju/'hoansi also recognized a form of ritual exchange, hxaro, which united trading partners who were not necessarily kin (Wiessner 1982, 1997). In addition, Ju/'hoansi established kinlike ties with people on the basis of having the same names as themselves or their relatives (Marshall 1965). Name relations, hxaro partners, kin, and 
affines were enmeshed in both reciprocal and delayed exchange relationships which served to even out the temporary risks of living in an economy in which surpluses of food or of material value could not be accumulated.

The pattern of life described above continued for some Ju/'hoansi into the 1950 s and 1960s. By the 1970 s even the most bush-oriented Ju/'hoansi were moving out of the bush toward permanent water sources. An impetus for this settlement was that in previous decades culturally and linguistically different populations of pastoral herders moved into areas previously occupied by Ju/'hoansi alone. Initially the villages established by the pastoralists, members of the Herero and Tswana ethnic groups, were attractive to the $\mathrm{Ju} /$ 'hoansi, who appreciated the milk and grain that pastoralists gave to $\mathrm{Ju} /$ 'hoansi in return for intermittent labor as cattle-hands and game scouts (Draper and Kranichfeld 1990). Over time as the numbers of pastoralists and their herds increased, the "pull" of attraction to the cattle camps became a "push" from behind as the increased numbers of people and livestock made the bush less attractive to the wild animals the Ju/'hoansi depended upon for hunting.

By the late 1980 s when the data for this study were collected, virtually all of the foragers were living in permanent villages around sources of permanent water. At the time of fieldwork some people had acquired small herds of their own. However, the great majority of Ju/'hoansi lived in poverty. ${ }^{2}$ Some worked for pastoralists but the great majority were dependent upon occasional government-supplied, wage-paying jobs and the periodic distribution of drought relief foods made available by the government to relieve the suffering of the rural poor throughout Botswana during the prolonged drought of 1981-1988 (Hitchcock 1988; Hitchcock et al. 1989). The interviewees for the present study were living in northwestern Ngamiland, Botswana, in the Xaixai, !Angwa, and N!aun!au river valleys. Many of the older informants (6o years and over) had spent their childhood and middle age living in the bush. Most of the middle-aged people (45 to 59 years) began their marriages and reproductive careers while living as part- or full-time hunter-gatherers.

In the next sections we use demographic data on a sample of middle-aged to elderly Ju/'hoansi who would have been born as early as about 1900 and as late as 1943 to investigate the relationship between a person's birth order and his or her fertility or reproductive success.

\section{Our Original Predictions}

We imagined two logical scenarios to explain a relationship between birth order and RS in a population of this type. First, we expected that the developmental advantage enjoyed by firstborns in other societies would be 
upheld among the Ju/'hoansi. We imagined that children born to relatively young parents would profit from their health and vigor. As first-born, they would have the benefit of a longer span of overlapping years with their parents who would play pivotal roles in negotiating favorable marriages for them. Younger children ran the risk of being orphaned while still socially immature. Recognizing the importance of kin ties in this society, we reasoned that firstborn children would be more likely to enjoy for a longer time the acquaintance and nurturing from their grandparents as well as uncles and aunts. These advantages, we reasoned, might result in better nutrition, health, and social support and could conceivably carry over into earlier ages at marriage and higher reproductive success. ${ }^{3}$ Further, as parents aged their siblings might die or, if still alive, would become more involved in the care of their own children and have fewer resources available to share with their nephews and nieces. Later born children would have fewer years of shared life with grandparents, who, several studies suggest, are likely sources of resources for grandchildren (Hawkes et al. 1989, 1997; Hill and Hurtado 1997a, 1997b; Turke 1997).

Our second prediction was that in Ju/'hoan society, birth order would bear no relationship to reproductive success. Our reasoning was based on the observation that daily life in the small, densely settled living camps gave everyone very intimate and daily contact with the 20 to 40 other residents of the camp. We expected that the experience of living in Ju/'hoan camps would be comparable to growing up in a large extended family or compound. Just as the westernized children studied by contemporary social scientists were almost all reared in nuclear families, when our Ju/'hoan interviewees were children they were reared in small, intimate villages and camps composed of kin, in-laws, and their children.

A third prediction developed out of the data analysis and the trends that were revealed between birth order and reproductive success. We present these data and discuss the development of our thinking about the contributions that the adult siblings of a parent can make to that that person's reproductive success.

\section{Statistical Methods}

The data consists of 319 reproductive history interviews gathered by Patricia Draper in 1987 and 1988. Of these, 175 individuals were older than age 45 and have been selected for analysis. ${ }^{4}$ Draper divided the data into two developmental age categories representing individuals between the ages of 45 and 59 and those 60 years or older. ${ }^{5}$ Clearly, some of the men in these two categories have not completed their reproductive careers while all of women have. Nevertheless, it is reasonable to assume that the residual reproductive 
output of individuals in these age categories is likely to be tiny and it will not significantly affect our analysis. A $t$-test reveals that there is no significant difference in fertility in these two age groups (see Figure 1).

Of the individuals in our sample, 16 men and 9 women (14\%) have failed to reproduce, and these individuals were withdrawn from the analysis that follows. While some of these infertiles could have suffered from primary infertility, this rate is much higher than the $1 \%$ to $5 \%$ found in tribal and modern populations (Campbell and Wood 1988; Wood 1994:448). It is highly likely that a substantial majority of these individuals suffered from secondary infertility. Secondary infertility was not associated with either birth order or number of siblings: mean birth order was 2.48 for infertiles and 2.67 for fertiles (two-tailed $t$-test, $p=0.345$ ). There was no significant difference in the number of siblings for fertile individuals (4.68) and infertile individuals (4.25) (two-tailed $t$-test, $p=0.239$ ). The contribution of venereal diseases to infertility among the Ju/'hoansi (!Kung) (Howell 1979) and in southern Central Africa is discussed by Belsey (1976; also see Caldwell and Caldwell 1983; Harpending and Draper 1990).

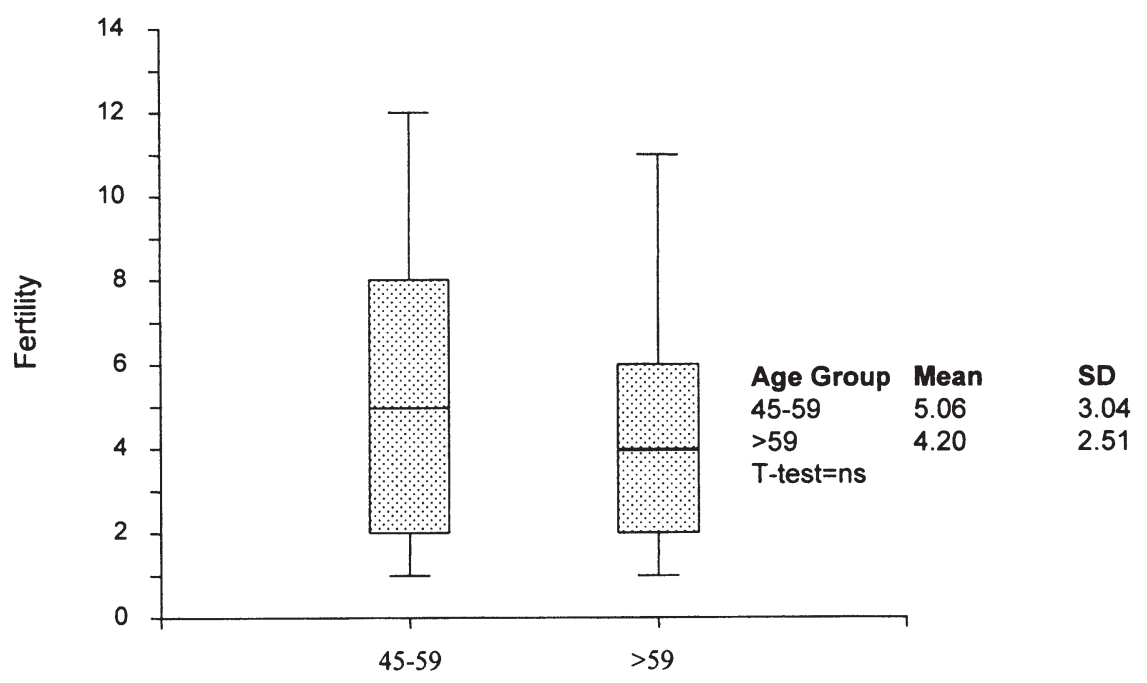

Age Cohorts

Figure 1. Fertility and two developmental age categories. Fertility is not statistically different between developmental age categories 45 to 59 years and greater than 59 years. 
We also deleted eleven women from the sample based on their marriage to men who were Herero pastoralists, a people culturally and linguistically unrelated to Ju/'hoansi. The reproductive performances of such women were likely to be biased as a consequence of social, cultural, and economic factors over which we had no analytical control. Our final sample size, following the above-mentioned deletions, is 69 men and 78 women for a total of 147 people.

Reproductive history interviews were collected on both the subjects' marital and reproductive histories and those of the subjects' parents. Consequently we had information on our subjects' birth orders and on which of their siblings had survived to the time of interview. In this paper the factors of birth order, number of older siblings, and total siblings are critical factors we associate with fertility and offspring survivorship. ${ }^{6}$ All statistical analyses were carried out by SPSSC) 8.0 for Windows 98.

\section{Analysis}

In our analysis of the consequences of birth order for fertility we draw several distinctions among the features of sibling configuration. We distinguish among birth order, number of older siblings, number of siblings, and number of currently living siblings. We believe these distinctions are theoretically important, and we will show in a series of analyses that these refinements of the independent sibling variable produce successively better correlations with our dependent variable, fertility, and in some cases, survivorship.

Birth order is an uncomplicated variable that refers to ego's sequential place in his mother's various full-term gestations. This measure is independent of whether previous siblings are alive or dead. For example, a third born could have no older siblings at the time of his or her birth if they died before he was born. Our measure of birth order considers ego's birth order from the point of view of the mother only. It is possible for a given ego to have a birth order that is different from maternal birth order for reasons of parental divorce or death and remarriage. In this paper birth order is calculated exclusively through the mother. We believe this is reasonable because Ju/'hoan children born to a common mother almost always remained together during their childhood and adolescence.

Number of older siblings is calculated as birth order minus one. It is an interval-level variable that is designed to measure the number of older siblings who are likely to behave nepotistically towards ego. As such, number of older siblings conceptually places this research in the kin selection domain of inclusive fitness theory as opposed to parental investment theory. We believe that having older siblings is important to a person in this egal- 
itarian society where there is no significant accumulation of wealth and no tendency for parents to favor firstborns over later borns or males over females in inheritance. The more older siblings available to a person, the more resources and assistance are available because of the siblings' direct and indirect assistance to ego. Siblings have a different value to ego, in comparison with parents, because sibs are closer in age to ego, whereas parents are at least 20-25 years older. Parents are therefore less able than siblings to provide nepotistic support over time. Parental investment is essential in the early childhood years and undoubtedly affects crude survivorship of children. However, in an egalitarian society, the gains of sibling access may have more import for a person's fertility once he or she has become an adult, in comparison with access to parents. As a person enters adulthood, one or both parents may be dead.

Number of siblings or sibset size refers to the total number of siblings and half siblings possessed by a particular ego. In our calculations we include full sibs and half sibs who are related through either the mother or the father. In our analyses we weighted full sibs as one and half sibs as one half.

The variable, number of currently living siblings, represents a further refinement in our way of thinking about siblings as a resource. As stated earlier, all our informants were middle-aged to elderly people. We recognized that some or all of the sibs of a mature adult were dead by the time of interview. Yet if some or many of those deceased sibs had lived for some years past childhood, particularly into an overlap with the informant's reproductive years, they could have had a positive effect on our informants' lives and opportunities. Since our youngest informants were 45 years old, the chances were that all of their living siblings were themselves adults, most probably married, and able to offer practical help directly to our informants and indirectly through our informants' access to their siblings' relations through marriage.

In other words, the variable of currently living siblings, though it ignores years of shared time with dead siblings, has certain advantages over the variables birth order, number of siblings, and number of older siblings. The currently living siblings of our middle-aged to elderly informants were all sufficiently mature to have been potent social and economic resources to the informants, even though some were younger than the informants. We expected that a measure of currently living sibs, as it applied to people in their middle to older years, was a proxy for lifetime sibling help. People may have had more sibs in the past, but they would not have had fewer.

We wish to clarify the issue of coresidence among siblings. Except for the time of the interview, we have no data on the whereabouts of siblings over their past life spans. Particularly among the older informants whose early adult years may have been spent in small/ mobile, foraging camps, there is no 
reason to expect that siblings regularly shared common camps and were able to assist one another directly, though this was undoubtedly the case in some instances. Ju/'hoansi regarded siblings as equally though differently valuable when they lived at a distance. They regarded it as good practice to have kin in a different territory (known as a $n$ !ori), for they could be visited for prolonged periods when the resources of a particular area were exhausted.

\section{Birth Order and Fertility}

In our first analysis we will determine whether there are relationships between our informants' birth orders, their fertility, and the survivorship of their children to age 5 . By fertility we simply mean the sum of live births produced by the women and men in our sample. Given the age of women and men in our sample, this measure very closely approximates total completed fertility. Our measure of the dependent variable survivorship is not as precise as perhaps it should be. Demographers measure survivorship as the percent of children ever born who reach various age categories (typically five, ten, fifteen, or twenty years). Our measure of survivorship among our informants' offspring is slightly different since it is based on the reproductive histories of men and women who are 45 years of age and older. As a consequence, some may have been producing or capable of producing offspring at the time they were interviewed. However, studies by Howell (1979) indicate that mean age at last birth among San women is 37 years with a mode between 40 to 44 years. Our measure of survivorship is defined as the proportion of children ever born who survived to age 5 . It is possible that some of the 45-year-old women and an unknown but undoubtedly larger fraction of men had children born to them several years earlier who would be counted as surviving to age 5 , when in fact they were younger than that threshold.

As shown in Table 1 and Figure 2 there is a significant correlation between birth order and reproductive success (fertility) for males and females combined (Spearman rank-order $r_{s}=0.227, p=0.008$, two-tailed). However, if we look at males and females independently, we find no significant correlations, although they are reasonably close to the 0.05 level of significance. The correlations between the informant's birth order and the survivorship of his or her offspring are not close to statistical significance in any of the cases.

\section{Number of Older Siblings, Fertility, and Survivorship}

The correlation between birth order and fertility led us to think about the specific mechanisms that might enhance fertility in the context of birth order. 
Table 1. Birth Order in Relation to Fertility (all tests twotailed. Spearman rank-order correlation coefficients)

\begin{tabular}{ccc}
\hline Sex & Fertility & Survivorship \\
\hline Male & & \\
$r_{s}$ & 0.221 & 0.146 \\
$p$ & 0.072 & \\
Female & & \\
$r_{s}$ & 0.209 & -0.004 \\
$p$ & 0.065 & \\
Both & & 0.069 \\
$r_{s}$ & 0.227 & 0.425 \\
$p$ & 0.008 & \\
\hline
\end{tabular}

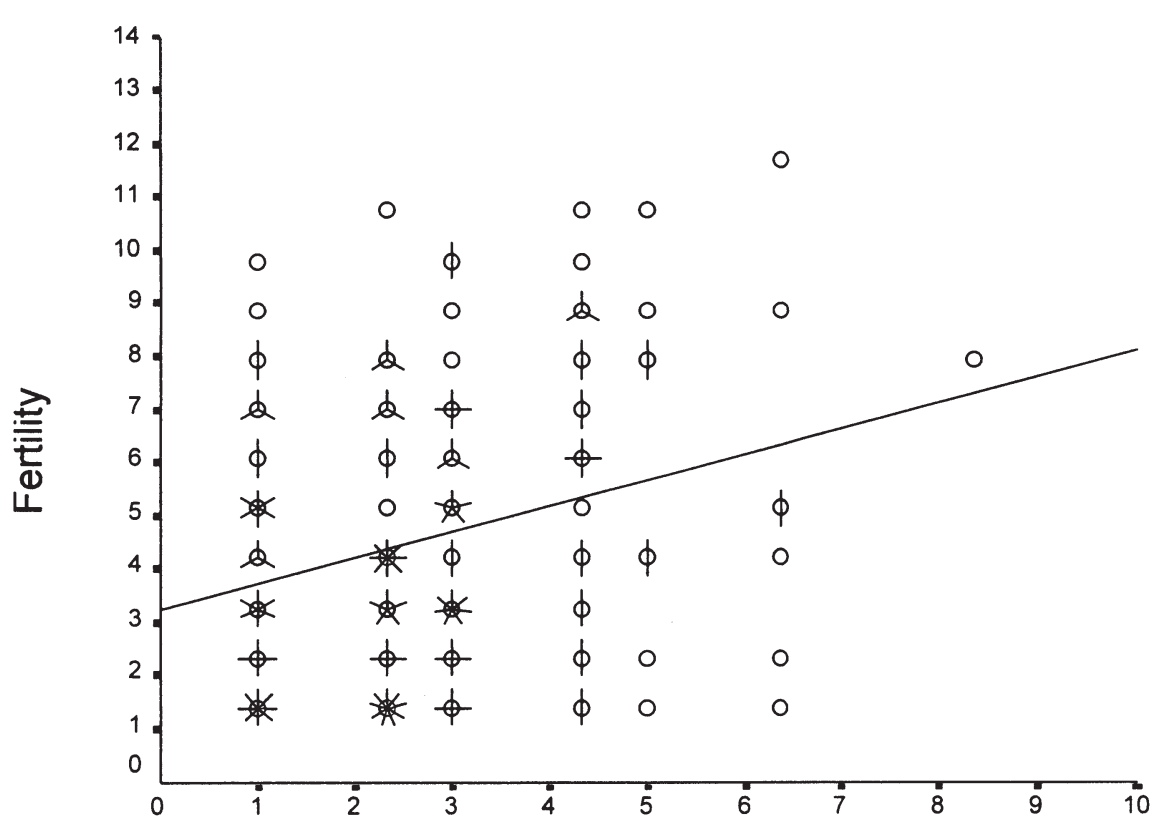

\section{Birth Order}

Figure 2. The effects of birth order on the fertility of Ju/'hoansi men and women. Spearman rank-order correlation coefficient $r_{s}=0.227, p=0.008$. Key: circle $=$ one case; circle with single line ending at midpoint = two cases; circle with two lines meeting at midpoint to form one vertical line = three cases; circle with three lines meeting at midpoint $=$ four cases, etc. 
In a weakly stratified society where capital resources are not differentially owned, kin become the critical resource for an individual's well-being and reproductive success. Kin, more than unrelated individuals, can be counted on to provide food, labor, and childcare assistance as well as social and political support. This generalization is consistent with basic findings in anthropology (e.g., Sahlins 1965) and expectations from inclusive fitness theory (Alexander 1974, 1979). This led us to consider two specific mechanisms that could enhance an individual's fertility: number of older siblings and total number of siblings.

First we turn to number of older siblings. We hypothesized that the greater the number of older siblings an individual has, the more economic or social support that he or she might receive which could be converted to the enhancement of fertility and/or survivorship of offspring. Siblings ought to be highly motivated to assist one another because they are related, on average, to one another by a factor of 0.50 (or 0.25 in the case of half sibs). Furthermore, the relationship between older and younger siblings is likely to be that of super donor to super recipient, respectively. This is because older siblings are more likely to be competent economic actors who have the ability to invest in close kin while younger siblings are less likely to be socially and economically adept (Alexander 1974, 1979).

To calculate number of older siblings per individual we took the birth order measure and subtracted one. For example/ if an individual's birth order was third that means that he or she has two older siblings. We then regressed this measure on fertility, this time using a Pearson product moment correlation coefficient because the new variable is an interval level of measurement. Obviously/ this analysis assumes that one's older siblings have survived long enough to be of use to ego and that some of them, some of the time, were spatially close enough to render assistance to ego. There are significant correlations between number of older siblings and reproductive success for males and females combined and for males and females alone (Table 2). Although number of older siblings is uncorrelated with survivorship in any of the comparisons, it comes close to significance for males. The data indicate that having begun life with a large number of siblings increases one's fertility. (Notice we have not yet considered whether these older siblings were alive at the interview or in the recent past.)

\section{Number of Siblings, Living Siblings, and Fertility and Survivorship}

Total number of siblings may be a significant factor for an individual's fertility for many of the same reasons outlined above in relation to number 
Table 2. Number of Older Siblings and Fertility (all tests two-tailed, Pearson product moment)

\begin{tabular}{ccc}
\hline Sex & Fertility & Survivorship \\
\hline Males & & \\
$r$ & 0.260 & 0.215 \\
$p$ & 0.033 & 0.081 \\
Females & & \\
$r$ & 0.290 & 0.076 \\
$p$ & 0.017 & 0.540 \\
Both & & \\
$r$ & 0.271 & 0.147 \\
$p$ & 0.001 & 0.089 \\
\hline
\end{tabular}

of older siblings. Our interest in this factor is based on two considerations. In Ju/'hoan culture the sibling tie is strong and affects reciprocity and exchange of visits throughout a person's life. We believe another factor may be at work to increase the potential of large sib sets to be a positive influence in a person's life (Lee 1979:60-67). Other Ju/'hoansi recognize relatively large sib sets as a social and political resource for the sib set members. We reason that nonrelatives who are matchmaking for their kin may preferentially seek marriages with people who have numerous siblings. If true, then the younger children of larger sib sets, when they reach marriageable age, may seem especially desirable as mates, since their older sibs are proof of an existent resource. The relatives of men and women who are marrying later-born brides or grooms may give them greater support because they recognize their future prospects are better. In comparison, once early born children of a large sib set reach marriageable age they may not seem especially desirable from the point of view of the relatives of the in-marrying spouses. The oldest child, for example, may be of marriageable age, but his or her siblings will still be relatively immature and without reputations as seasoned and competent individuals. Outsiders may reason that the younger sibs of an early born bride or groom are not social assets. The junior sibs are young and dependent, and no one can know if they will survive to an age at which they will become socially valuable. Furthermore, younger sibs of a marriageable man or woman may be seen as competitors to the spouse and his or her future children. In other words, we argue that the developmental stage of the sib set has different consequences for persons differently positioned within it. This could explain our findings for birth order, reported in Figure 2. For men and women combined, the higher the birth order, the higher the fertility. We consider the gender differences in our findings in a later section. 
Number of siblings (or number of siblings ever born) is the sum of all siblings of ego who shared a common mother and father (full sibs) and siblings of ego with a common father or mother (half sibs). In calculating number of siblings, full sibs were counted as one and half sibs as one-half. For women alone there is no significant correlation between number of siblings and fertility or survivorship. However, there is a significant correlation among men between number of siblings and fertility (Table 3 and Figure 3) which is stronger than the relationship between number of older siblings and fertility.

The number of ego's siblings ever born in relation to ego's fertility is problematic because it does not tell us how long ego's siblings were alive. In an extreme case an ego could have had five siblings, all of whom died before ego was born. If cooperation among siblings is to occur, there must be some time overlap between the lives of siblings. In the best of all methodological worlds/ for each ego we would like to calculate number of siblings ever born weighted by the number of years that each sibling lived contemporaneously with ego. This would provide us with a measure of potential lifetime availability for cooperation. It would be even more desirable to add years of coresidence to this measure since siblings are more likely to cooperate intensively if they co-reside. Because we do not have these data we decided to create a measure called "number of living siblings," which is the number of living siblings an individual had at the time of the interview. Given the way in which the data were collected, this is the best proxy we had for lifetime availability of siblings. For all the reasons enumerated above, we believe that this factor is more likely to be a superior predictor of reproductive success than number of siblings ever born. Changing the measure from total siblings ever born to currently living siblings increases the fertility correlation significantly for males but only marginally for females (Table 4, and for males. Figure 4).

Table 3. Number of Ego's Siblings Ever Born and Fertility and Survivorship (all tests two-tailed, Pearson product moment)

\begin{tabular}{ccc}
\hline Sex & Fertility & Survivorship \\
\hline Male & & \\
$r$ & 0.307 & 0.140 \\
$p$ & 0.014 & 0.270 \\
Female & & \\
$r$ & 0.098 & 0.007 \\
$p$ & 0.407 & 0.955 \\
Both & & \\
$r$ & 0.186 & 0.056 \\
$p$ & 0.030 & 0.513 \\
\hline
\end{tabular}




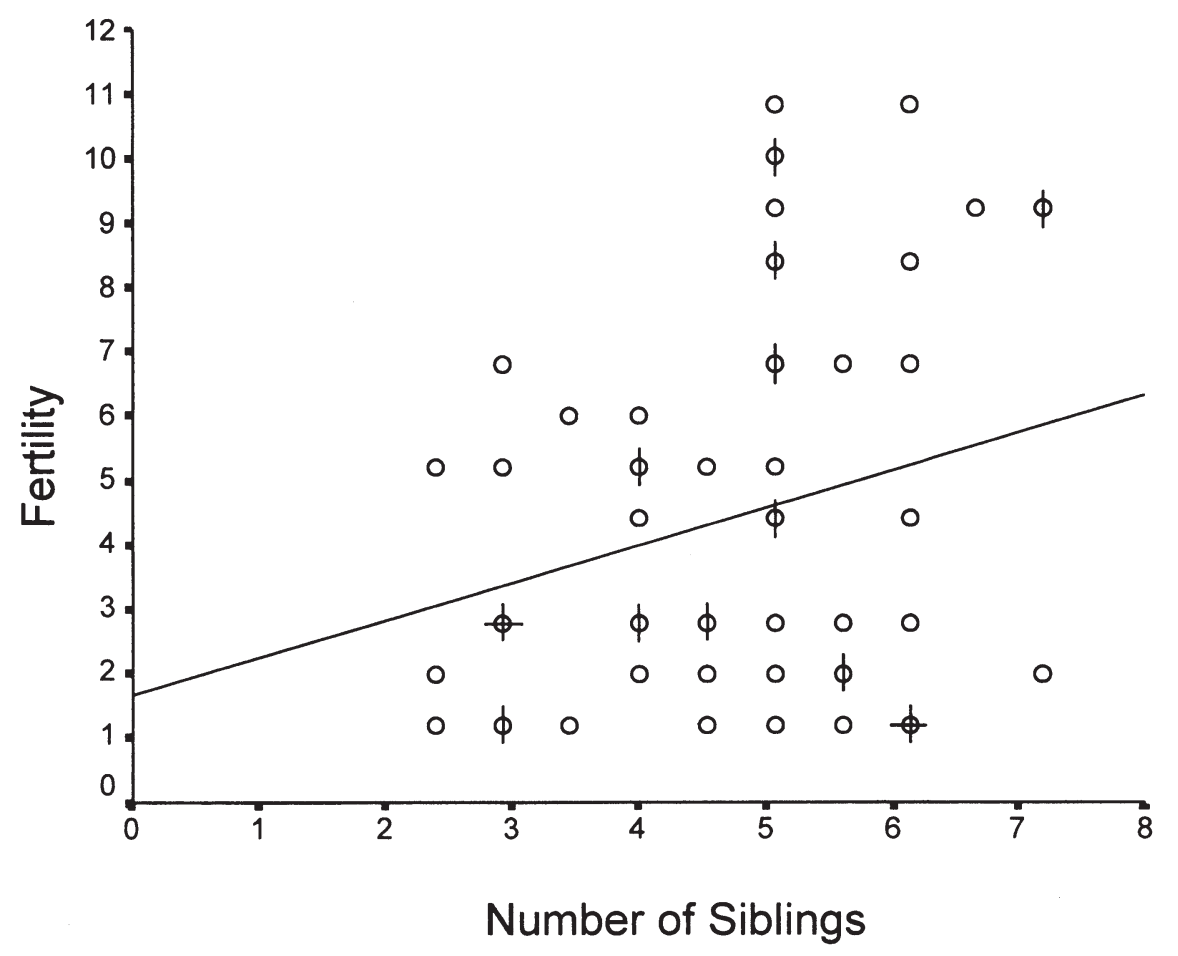

Figure 3. The effects of number siblings on the fertility of Ju/'hoansi men. Pearson's $r=0.307, p=0.014$.

\section{Number of Older Siblings and Total Living Siblings as Predictors of Fertility and Survivorship}

The preceding analysis indicates that birth order, number of older siblings, total siblings, and total living siblings are positively correlated with fertility. The next step is to perform a multiple regression analysis to determine if some of these factors combined can explain more of the variance in fertility and survivorship. We have chosen to examine number of older siblings and number of currently living siblings. We chose number of older siblings over birth order because we believe fertility enhancement is mediated by number of older siblings per se and not its correlate, birth order. Obviously, we cannot use both factors because they are perfectly correlated. We chose number of living sibs over total siblings for theoretical reasons outlined earlier: siblings must be available for a significant portion of an individual's lifetime for 
Table 4. Number of Living Siblings and Fertility and Survivorship (all tests two-tailed, Pearson product moment)

\begin{tabular}{ccc}
\hline Sex & Fertility & Survivorship \\
\hline $\begin{array}{ccc}\text { Combined } \\
r\end{array}$ & 0.255 & \\
$p$ & 0.003 & 0.097 \\
Males & & 0.260 \\
$r$ & 0.447 & \\
$p$ & 0.000 & 0.172 \\
Females & & 0.174 \\
$r$ & 0.076 & \\
$p$ & 0.524 & 0.038 \\
\hline
\end{tabular}

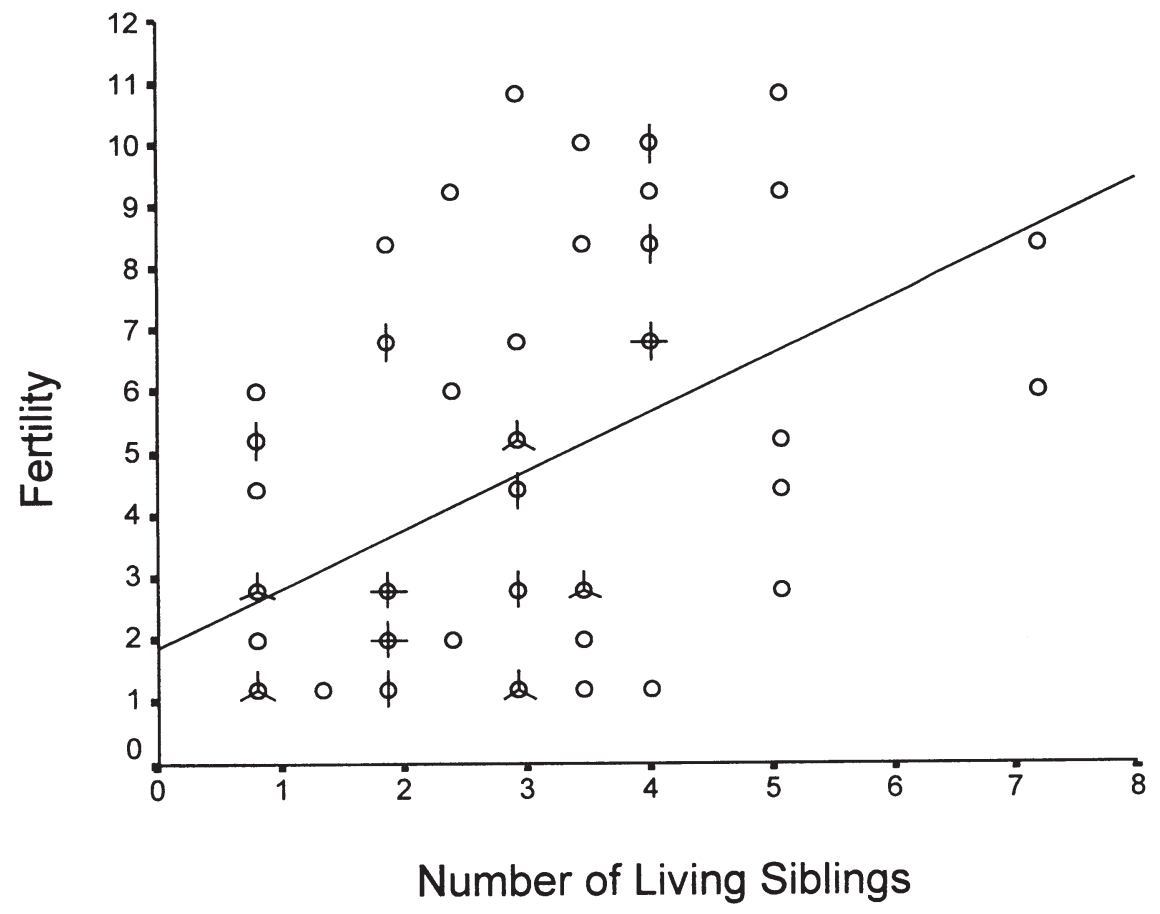

Figure 4. Fertility and number of living siblings for Ju/'hoansi men. Note that men may have fractional siblings because half sibs were counted as 0.5 siblings. Pearson's $r=0.447, p=0.000$. 
positive kin effects to occur. Number of older siblings and number of living siblings can be employed as independent factors because they are uncorrelated for men $(p=0.302)$, women $(p=0.635)$, and men and women combined $(p=0.207)$. Entering both variables in a block, the correlation coefficients are $r=0.319(p=0.001)$ for men and women, $r=0.239$ for women $(p$ $=0.119)$, and $r=0.484(p=0.000)$ for men. The low correlation for women (only $5 \%$ of the variance in fertility is accounted for by the two factors for women), and lack of significance, is a consequence of the fact that the bivariate correlation between number of older siblings alive and fertility is not significant (see above Table 4 above). However, our model accounts for an impressive $24 \%$ of the variance in male fertility. In addition, this model comes close to statistical significance for men $(p=0.066)$ in predicting survivorship of offspring to age 5 .

\section{Discussion}

Our first hypothesis that early born Ju/'hoan children would have higher reproductive success than later born children was not confirmed. In fact, the correlation between birth order and fertility was significantly positive, al-

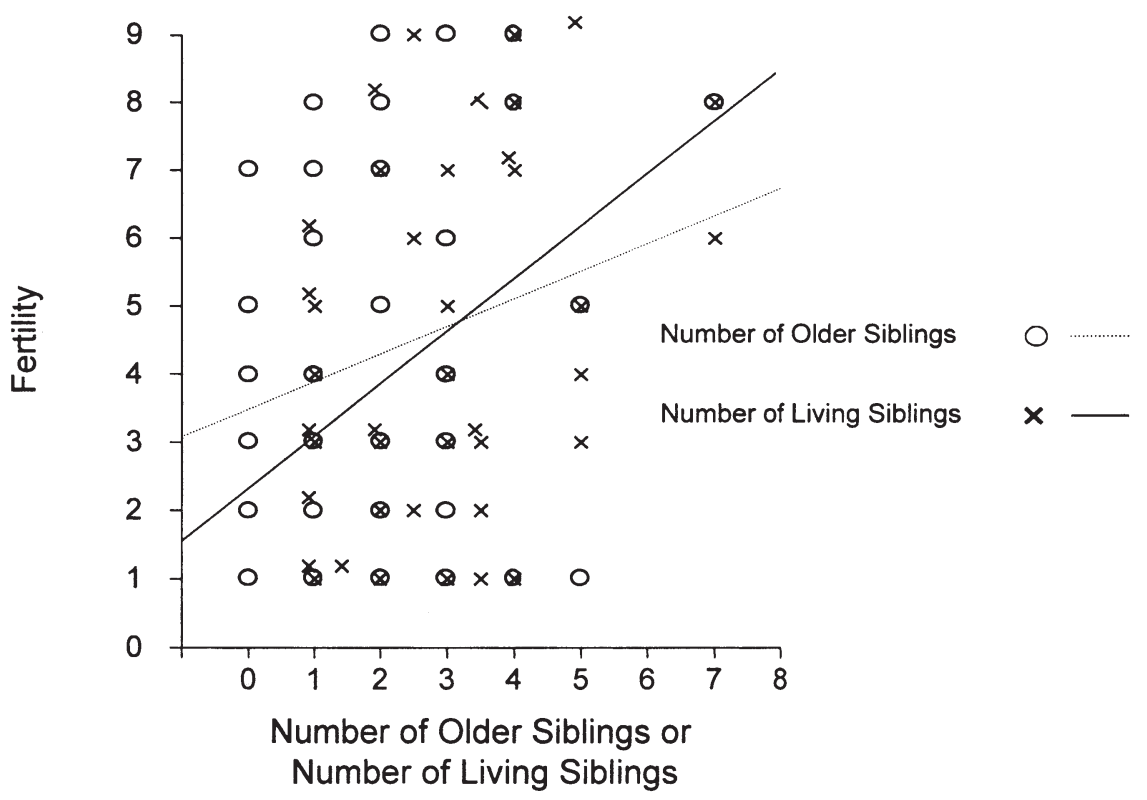

Figure 5. Fertility and number of living siblings and number of older siblings for $\mathrm{Ju} /$ 'hoansi men. Multiple correlation coefficient $r=0.484, p<0.001$. 
though it did not hold when the sexes were considered separately. Our second hypothesis, that household organization and settlement pattern would produce a pattern of no relationship between birth order and reproductive success, was also not supported. This led us to consider other sibling set characteristics that might logically be associated with fertility. In doing so we switched from parental investment considerations, upon which some of the birth order literature is theoretically based, to a focus on nepotism among siblings over the lifespan.

Some recent studies of traditional peoples have considered the sexual composition of sibling groups and its influence on marriage in tribal societies stratified by wealth. For example, among Gabbra pastoralists Mace (1996:78) found that male birth order was negatively associated with reproductive success: males with many older brothers had lower fertility. Fertility was lowered because lastborn Gabbra men had a smaller initial bridewealth herd and married at later ages in comparison with their older brothers. Number of elder sisters had no impact on female fertility, whereas number of sisters in a family had moderately positive effect on a brother's reproductive success. Among the Kipsigis, Borgerhoff Mulder shows a positive correlation between number of sisters and reproductive success for men and a negative correlation between number of brothers and reproductive success for men (Borgerhoff Mulder 1998). Sibling set composition by gender (or apparently by number) has no effect on female reproductive success. In the Gabbra and Kipsigis cases, the ability of parents to invest in sons in the form of livestock paid as a brideprice steadily declines with increasing number of boys. Following the maternal depletion syndrome in analogous fashion, one could characterize this phenomenon as a parental depletion syndrome: parental resources are exhausted with increasing numbers of expensive offspring.

Two studies show a positive correlation between sibling set size and reproductive success of siblings. These studies, as we will argue below, suggest that this relationship may be a consequence of kin altruism. Recent research by Heath (1996) on a United Order commune of Mormons in the 1880 os reveals a correlation between number of brothers in a family and fertility: a man who had many brothers had higher fertility than a man with fewer brothers. Number of brothers or sisters or total siblings had no impact on a woman's reproductive success. For men with many brothers, higher reproductive success was achieved by early marriage, marriage to young women, and perhaps a greater likelihood of polygyny. According to Heath (University of Utah, personal communication 1999), women find men with many brothers attractive because, given the patrilateral residence pattern, brothers cooperate in agricultural pursuits, creating economies of scale and enhancing household wealth. In addition, she believes that high male productivity may spare women from field labor, which may permit them to space births more closely. ${ }^{7}$ 
Hill and Hurtado's work on the Aché is the other study that demonstrates a positive correlation between number of siblings (or number of male siblings, in the Mormon case) and reproductive success for men, a pattern which is absent for Ache females (Hill and Hurtado 1996:426-427 and Table 13.5). These biased sex results are identical to our own for Ju/'hoansi. This requires us to consider two issues: (1) Why do the Ache and Ju/'hoansi results show positive correlations between sib set size and fertility opposite those of the Gabbra and Kipsigis? (2) Why does this relationship only hold for males? In regards to the first issue, it is relevant that the Gabbra and Kipsigis are stratified by wealth, have brideprice, and are characterized by resource defense polygyny. That is, one's ability to have high fertility depends on wealth of one's parents and one's own efforts in acquiring additional wealth for brideprice. For both the Ache and Ju/'hoansi, brideprice is absent and polygyny either exists at very low levels (Ju/'hoansi) or is reduced to an extreme form of serial monogamy for some men (Ache). The Mormons studied by Heath, however, are polygynous but they lack brideprice. Therefore, sons among the Mormons, Ache, and Ju/'hoansi are not competing for scarce parental resources in order to accumulate the brideprice necessary for marriage. However, this reasoning simply argues that later borns should not be disadvantaged, and it does not help us understand why males of large sibling sets are reproductively advantaged, but not females.

We suggest that having many siblings significantly increases an individual's network of altruists who may render aid in times of need. This aid is likely to be in the form of food, assistance in childcare, access to foraging territories occupied by dispersed siblings, and political support in times of conflict. In a different sociopolitical context, Casimir and Rao signal the value of large numbers of closely related males when they note that sons and brothers are critical in forming the "basis on which a family can endeavor to preserve pastures, form coalitions, create new sub-factions, break up old factions, and thereby win over or destroy competing stockowners" (Casimir and Rao 1995:258).

This brings us to the question of why lastborns have higher fertility than firstborns. If having a large number of siblings enhances fitness, at least for males, then lastborns will have greater numbers of sibling altruists over the course of their lifetimes than firstborns. Firstborns initially have no siblings. Through time they may or may not accumulate siblings who would be in a position to render them assistance towards enhancing their fitness. Lastborns, in contrast, are much more likely to have siblings early on. The correlation between birth order (or number of older siblings) and number of siblings is $r=0.40, p>0.000$ for both sexes, $r=0.281, p=0.024$ for males, and $r=$ $0.468, p>0.000$ for females. Just as importantly, lastborns will have more older siblings who are in a position to give them effective assistance over the 
course of their reproductive lifespan because older sibs are more economically and politically skilled. Firstborns, in contrast, will have younger siblings who because of their age will have less economic competence and social status. This disparity in social competence among sibs should wane over time. However, we reason that later born sibs reap an advantage in their early adult years when they are marrying and starting families, whereas first and early borns lack this advantage.

The opposite correlation between birth order and fertility found in stratified and egalitarian societies may be interpreted in the following way. In a stratified society lastborns enter a destitute world where parental resources are spent and older offspring can outcompete them for parental resources. For the most part, the resources older offspring accumulate are parlayed into additional wives for themselves or their sons. In an egalitarian system, lastborns enter a socially enriched environment. Their older brothers and sisters are socially and economically competent and have the ability and motivation to assist younger siblings. Material wealth is not accumulated for reproductive ends. Instead, wealth is embodied in the number of close kin and social allies. These advantages powerfully enhance a lastborn's fertility and survivorship of his or her children.

We do not understand why it is that our adult interviewees who were first or early born were not able to benefit from the nepotistic help of their own parents and their own parents' brothers and sisters. For example, it is reasonable to suppose that early born children who became parents themselves had the advantage of their own parents' help directed to the grandchildren (the offspring of our informants.) Later born children were less likely to have surviving parents and, in any case, their parents were presumably at less vigorous stages of their life spans. Perhaps in Ju/'hoan society, parents are important for an individual's survivorship and well being in the child and juvenile phases of life. However, by the time our informants were of marriageable age and beginning their reproductive careers, their own parents were of less value for several reasons: they may have died, have become enfeebled, or diverted their investment to any remaining dependent younger brothers or sisters.

Why did our early born informants not benefit from the nepotistic help of their own parents' brothers and sisters (the uncles and aunts of the informants)? Perhaps this effect operated but was unmeasured because we knew our informants' birth orders but not the birth order of our informants' parents. In other words, the parents of our informants doubtlessly represented a mixture of sibling positions and therefore were variable in terms of gaining help from their sibs.

It is possible that large-scale, secular changes explain some of our observations. For example, there may be an interaction effect of sedentarization of the $\mathrm{Ju} /$ 'hoansi that intensified after the 1940 s and the particular cohorts 
whose reproductive success we measured in the 1980s. For example. Draper and Howell report findings from a reanalysis of demographic data gathered by Howell from the 1960s. Howell's data come from the completed fertility histories of women who were postmenopausal in the late 1960s, 20 years earlier than the time Draper collected the data reported in this paper. Howell's data show that early born children were more likely to retain a greater dependence on hunting and gathering, whereas later born children were more likely to have moved to the cattle posts. Our finding for later born reproductive advantage evident in older adults interviewed in the 1980 may sample this kind of secular trend, particularly if the later born, cattle post-dwelling people had higher fertility than their older sibs who spent most of their reproductive careers living as foragers (Draper and Howell 1998). Preliminary analysis reveals that people in the present study who were between 45 and 59 years of age had higher fertility than those 60 years and older, but this difference is not statistically significant (see Figure 1). More detailed analysis of possible cohort effects will be discussed in a future publication.

It is puzzling that being a member of a large sib set (Table 3) and having a large number of living siblings (Table 4) has no effect on a woman's fertility. As far as we can determine the advantages of having large numbers of older siblings should be of equal advantage for men and women. If girls were typically expected to provide care for their younger siblings, whereas boys were not, this factor would work against any tendency for later born girls to profit from the help of their older sibs. For example, consider a sibship of several children ranging from 5 to 25 years of age for which one or both parents had died. If the female sib(s) were expected to assume more of the deceased parent's work, this increased load could delay a woman's age at marriage and might also reduce her fecundability when she married as a result of the greater energetic demands put on her (Bentley 1999). An effect of this type is reported by Turke (1988) for the Truk. In this case Turke showed that firstborn females had reduced fertility in comparison with their later born sibs. However, number of siblings had no effect on a male's fertility. This was apparently because Truk parents exacted more work from the older daughters, for example requiring them to mind younger siblings and to marry later as a result of their surrogate parenting duties.

Earlier research, done in the late 1960s, has shown that the Ju/'hoansi were very slow to press their children into economic service. In this society there was no tradition of assigning older children a formal responsibility as minders of younger sibs, as is common in agricultural societies where maternal workloads are heavy. Older, pre-reproductive children gave occasional help to younger sibs, but we have no empirical reason to believe this sort of responsibility would negatively affect the reproductive success of the older children (Draper 1976; Draper and Cashdan 1988; Draper and Harpending 
1987). Children did very little economically useful work (Draper 1975). Even twelve- and thirteen-year-olds (boys as well as girls), who in agricultural, pastoral, and some hunting and gathering societies can contribute substantially, were rarely observed in food gathering or in apprentice roles (Blurton Jones et al. 1994). On the other hand, it is possible that the costs of being firstborn in $\mathrm{Ju} /$ 'hoan society were levied later in the life course and disproportionately on girls and therefore would not have been observable to Draper when she collected systematic data on the behavior of children ages 3 to 14 years. Some information on this point could be gathered retrospectively by asking grown $\mathrm{Ju} /$ 'hoansi, both men and women, about whether they provided care to a younger sib or received care from an older sib who was acting for whatever reason as a surrogate parent. As our discussion reveals, if such a retrospective study were undertaken, whether in Ju/'hoan society or in another, it would be necessary to have birth order, fertility, and survivorship data on both the primary informant and his or her parents.

Perhaps the frequently reported differences in male versus female reproductive variance may be masking the actual benefits women received from siblings. For example, if, on the average, Ju/'hoan women were producing at close to their biological maximum under the historical conditions of the recent past, then the presence or absence of sibling set influences may have contributed little to female fertility. This led us to compute the variance in male and female reproductive success. These differences are not statistically significant (see Table 5). In this society, unlike many tribal populations, male and female reproductive success are essentially the same.

If it is true that $\mathrm{Ju} /$ 'hoansi find members of large sibling sets useful allies then we may have a basis for understanding why being a member of a large sib set has strong reproductive effects on male members and no effect on female members. If a male member of a large sib set loses a wife through divorce or death, he may be in a better position to marry a young woman with high residual reproductive value than a male who belongs to a small sib set. In addition, males of large sib sets may have lower divorce rates or, when they initially marry, may marry women of high reproductive values. We suggest males in large sib sets are more likely to remain attractive as potential mates regardless of their age. In contrast, if a woman from a large sib set loses a spouse because of death or divorce, her attractiveness as a poten-

Table 5. Male and Female Reproductive Variances

\begin{tabular}{lccccc}
\hline Sex & $N$ & Mean & s.d. & \multicolumn{2}{c}{ Levene's Test for Equality of Variances } \\
\hline Male & 69 & 4.507 & 2.87 & F & Significance \\
Female & 78 & 4.482 & 2.77 & 0.416 & 0.52 \\
\hline
\end{tabular}


tial mate would decline with age. Although a man may find such a woman potentially attractive because of her brothers and sisters, her attractiveness would be offset by her age and her interest in caring for children of a previous union. One way in which to test this hypothesis would be to compare rates of divorce, number of years in marital unions, and the reproductive value of spouses among men and women belonging to large sib sets. Finally, although polygyny is uncommon among $\mathrm{Ju} /$ 'hoansi it is possible that males of large sib sets are more likely to be polygynous compared with males of small sib sets. We plan to evaluate some of these hypotheses in a future publication.

\section{Confounds}

It is possible that the relationships we have established between sibling set characteristics and fertility are ultimately a consequence of other factors that predict both sibling set characteristics and fertility. We consider two possibilities below: the heritability of health and variation in parental investment.

It is possible that members of large sibling sets tend to have high fertility and survivorship of children simply because, on average, they are biologically healthier as individuals and this trait is reflected in their fertility. As we have shown in Table 3 there is a positive correlation between number of siblings and fertility for men ( $r=0.307, p=0.014$, two-tailed), but the relationship is absent for females ( $r=0.098, p=0.407$, two-tailed). If the heritability of fertility hypothesis were true we would expect that it would apply equally to men and women. However, it applies only to men.

One could argue that low birth order is associated with loss of a mother at an early age, which would reduce the amount of parental investment and could ultimately have negative consequences for future fertility. While there may be an association between low birth order and lack of parental investment, this is more likely to be the case for high birth order individuals, as discussed previously in another context. Because mortality is age-dependent, lastborns tend to have older mothers when they are born, which makes them more likely to capture fewer years of parental investment than firstborns, whose mothers were younger when they were born.

\section{Conclusion}

In summary, our study reports the unexpected finding that older $\mathrm{Ju} /$ 'hoansi, studied in the late 1980s, who were later born had higher fertility than their earlier born siblings. Further, number of siblings, number of living 
siblings, and number of older siblings are strong predictors of reproductive success, particularly for men. Our best explanation for this finding is that siblings in fact provide material and other resources to each other in a pattern that benefits younger sibs more than older sibs. We also suggest that Ju/ 'hoansi see later born children in large extant sib sets as better situated in a life career trajectory and therefore award them some kind of social distinction or precedence. Adult sibs may make sacrifices, both in terms of providing direct parental investment to their younger sibs and in disproportionately favoring their brothers and brothers' children over sisters and sisters' children. Conceivably, in the past brothers may have been more reliable as reciprocal pairs than brothers and sisters, leading to a fraternal bias in sibling exchanges that over time. Perhaps our study measures distant repercussions of these several dynamics.

$\diamond \diamond \diamond \diamond \diamond \diamond \diamond$

We wish to thank several readers of an earlier draft of the manuscript: Rada DysonHudson, Kim Hill, Nancy Howell, Magdalena Hurtado, and Alice Schlegel. We are grateful to Kathleen Heath for giving us information from her Ph.D. dissertation regarding the influence of male siblings on Mormon men's reproductive success.

Patricia Draper is a professor in the Department of Anthropology at the University of Nebraska. Her research interests are in cross-cultural human development, evolutionary theory, hunter-gatherer society, and comparative family organization.

Raymond Hames is also a professor in the Department of Anthropology at the University of Nebraska. His research interests are in behavioral and evolutionary ecology, exchange systems, and tropical forest peoples.

\section{Notes}

1. Historians and sociologists discuss similar processes of long-term familial interdependencies in modern, western society (Hagestad 1990; Hareven 1986; Kertzer 1986).

2. Research was supported by the National Institute of Aging, grant number AGo3110. Principal investigators were Christine Fry of Loyola University and Jennie Keith of Swarthmore College.

3. We know of no studies that report nutritional or growth differentials among $\mathrm{Ju} /$ 'hoan children of different birth orders.

4. The Ju/'hoansi do not know their own ages, but it is possible to assign ages to informants and to other living people named by informants on the basis of inference from known historical dates, previous age assessments by Nancy Howell (who worked with many of the same people), and informant reports about which individuals were born at approximately the same time. 
5. The age categories were chosen on grounds of changes Ju/'hoansi associated with biological aging and the verbal distinctions they applied in describing the aging process. The 45-59-year-old category captured middle-aged people who had passed out of vigorous adulthood but were not yet showing signs of frailty. In particular it corresponded with an age by which all women would have completed childbearing. The older category, 60 years and older, corresponded roughly with a western concept of chronological age and the socially recognized life stage at which Ju/'hoansi recognized both men and women as elders (niewsi).

6. As stated, we knew the approximate chronological ages of the informants. We did not know the ages of other people, living and dead, who were mentioned by the interviewees. An attempt was made to attach one of several approximate "developmental age codes" to all offspring mentioned by ego. Dead children were coded according to their age at death. The code followed $\mathrm{Ju} /$ 'hoan usage and distinguished among infants who could not walk (under one year); a walking child who was still nursing (2-4 years); a child who was kept close to adults (6-10 years); a grown but not sexually mature child (11-15 years); and an adolescent child (in the case of a girl, one who had menstruated; in the case of a boy, one who was showing interest in women), 15 years and over.

7. See Hewlett 1988:271 for evidence that Aka Pygmy women are attracted to men with numerous brothers.

\section{References}

Adair, L. S., E. Pollitt, and W. H. Mueller

1983 Maternal Anthropometric Changes during Pregnancy and Lactation in a Rural Taiwanese Population. Human Biology 55:771-787.

Alexander, Richard D.

1974 The Evolution of Social Behavior. Annual Review of Ecology and Systematics 5:325-383.

1979 Darwinism and Human Affairs. Seattle: University of Washington Press.

Altus, W. D.

1966 Birth Order and its Sequelae. Science (151):44-49.

Bailey, Robert C.

1988 The Significance of Hypergyny for Understanding the Subsistence Behavior of Contemporary Hunters and Gatherers. In Diet and Subsistence: Current Archaeological Perspectives, B. V. Kennedy and G. M. LeMoine, eds. Pp. 57-65. Calgary: University of Calgary Press.

Bayer, A. E.

1967 Birth Order and Attainment of the Doctorate: A Test of an Economic Hypothesis. American Journal of Sociology 72:540-550.

Beckerman, Stephen, Roberta Lizarralde, Carol Ballew, et al.

1998 The Bari Partible Paternity Project: Preliminary Results. Current Anthropology 39:164-167. Belsey, M. A.

1976 The Epidemiology of Infertility: A Review with Particular Reference to Sub-Saharan Africa. Bulletin of the World Health Organization 54:319-341.

Bentley, Gillian R.

1999 Aping Our Ancestors: Comparative Aspects of Reproductive Ecology. Evolutionary Anthropology 7(5):175-185. 
Blake, Judith

1986 Number of Siblings, Family Background, and the Process of Status Attainment. Social Biology 33:5-21.

1989 Family Size and Achievement. Berkeley: University of California Press.

Bledsoe, Caroline, and Gilles Pison, eds.

1994 Nuptiality in Sub-Saharan Africa: Contemporary Anthropological and Demographic Perspectives. Oxford: Clarendon Press.

Blurton Jones, Nicholas, Kristen Hawkes, and Patricia Draper

1994 Foraging Returns of !Kung Adults and Children: Why Didn't !Kung Children Forage? Journal of Anthropological Research 50:217-248.

Boone, James L., III

1986 Parental Investment and Elite Family Structure in Preindustrial States: A Case Study of Late Medieval-Early Modern Portuguese Genealogies. American Anthropologist 88:859-878.

1988 Parental Investment, Social Subordination, and Population Processes among the 15th and 16th Century Portuguese Nobility. In Human Reproductive Behavior: A Darwinian Perspective, L. Betzig, M. Borgerhoff Mulder, and P. Turke, eds. Pp. 201-220. Cambridge: Cambridge University Press.

Borgerhoff Mulder, Monique

1992 Reproductive Decisions. In Evolutionary Ecology and Human Behavior, E. A. Smith and B. Winterhalder, eds. Pp. 339-374. New York: Aldine de Gruyter.

1992 Women's Strategies in Polygynous Marriage: Kipsigis, Datoga, and Other East African Cases. Human Nature 3:45-70.

1998 Brothers and Sisters: How Sibling Interactions Affect Optimal Parental Allocations. Human Nature 9:119-162.

Bugos, Paul E., and Lorraine McCarthy

1984 Ayoreo Infanticide: A Case Study. In Infanticide, G. Hausfater and S. B. Hrdy, eds. Pp. 503-520. New York: Aldine.

Caldwell, H. C., and P. Caldwell

1983 The Demographic Evidence for the Incidence and Cause of Abnormally Low Fertility in Tropical Africa. World Health Statistical Quarterly 36(376):2-34.

Campbell, K. L., and J. W. Wood

1988 Fertility in Traditional Societies: Social and Biological Determinants. In Natural Human Fertility, P. Diggory, M. Potts, and S. Teper, eds. Pp. 3969. London: MacMillan.

Cashdan, Elizabeth

1983 Territoriality among Human Foragers: Ecological Models and an Application to Four Bushman Groups. Current Anthropology 24:47-66. Casimir, M., and A. Rao

1995 Prestige, Possessions, and Progeny: Cultural Goals and Reproductive Success among the Bakkarwal. Human Nature 6:241-272.

Chagnon, Napoleon A.

1979a Is Reproductive Success Equal in Egalitarian Societies? In Evolutionary Biology and Human Social Behavior: An Anthropological Perspective, N. A. Chagnon and W. Irons, eds. Pp. 374-401. North Scituate, Massachusetts: Duxbury Press. 
1979b Mate Competition, Favoring Close Kin, and Village Fissioning among the Yanomamo Indians. In Evolutionary Biology and Human Social Behavior: An Anthropological Perspective, N. A. Chagnon and W. Irons/ eds. Pp. 86-132. North Scituate, Massachusetts: Duxbury Press.

1982 Sociodemographic Attributes of Nepotism in Tribal Populations: Man the Rule Breaker. In Current Problems in Sociobiology, Kings College Sociobiology Group, ed. Pp. 291-318. London: Cambridge University Press.

Cronk, Lee

1989 Low Socioeconomic Status and Female-Biased Parental Investment: The Mukogodo Example. American Anthropologist 91:414-429.

1991 Wealth, Status and Female-Biased Parental Investment: The Mukogodo Example. American Anthropologist 93:345-360.

Daly, M., and M. Wilson

1981 Abuse and Neglect of Children in Evolutionary Perspective. In Natural Selection and Social Behavior, R. D. Alexander and D. W. Tinkle, eds. Pp. 405416. New York: Chiron.

1987 The Darwinian Psychology of Discriminative Parental Solicitude. Nebraska Symposium on Motivation 35:91-144.

1988 Homicide. Chicago: Aldine.

Davis, Daniel J., Sorel Cahan, and Joseph Bashi

1977 Birth Order and Intellectual Development: The Confluence Model in the Light of Cross-cultural Evidence. Science 196:1470-1472.

Davis, Jennifer Nerissa

1997 Birth Order, Sibship Size, and Status in Modern Canada. Human Nature 8:205-230.

Dickemann, M.

1979 The Ecology of Mating Systems in Hypergynous Dowry Societies. Biology and Social Life 18(2):163-195.

1981 Paternal Confidence and Dowry Competition: A Biocultural Analysis of Purdah. In Natural Selection and Social Behavior: Recent Research and New Theory, R. D. Alexander and D. W. Tinkle, eds. Pp. $417^{\wedge} 38$. New York: Chiron Press.

Draper, Patricia

1973 Crowding among Hunter Gatherers: The !Kung Bushmen. Science 182: 301-303.

1975 Cultural Pressure on Sex Differences. American Ethnologist 2:602-616.

1976 Social and Economic Constraints on Child Life among the !Kung. In Kalahari Hunter-Gatherers, R. B. Lee and I. Devore, eds. Pp. 199-217. Cambridge: Harvard University Press.

1992 Room to Maneuver: !Kung Women Cope with Men. In Sanctions and Sanctuary: Cultural Perspectives on the Beating of Wives, D. A. Counts, J. K. Brown, and J. C. Campbell, eds. Pp. 43-61. Boulder: Westview Press.

Draper, Patricia, and Anne Buchanan

1992 If You Have a Child, You Have a Life: Demographic and Cultural Perspectives on Fathering in Old Age in !Kung Society. In Father-Child Relations: Cultural and Biosocial Contexts, B. Hewlett, ed. Pp. 131-152. New York: Aldine de Gruyter.

Draper, Patricia, and Elizabeth Cashdan

1988 Technological Change and Child Behavior among the !Kung. Ethnology 27:339-365. 
Draper, Patricia, and Henry Harpending

1987 Parent Investment and the Child's Environment. In Parenting across the Lifespan: Biosocial Dimensions. ]. B. Lancaster, A. S. Rossi, J. Altmann, and L. R. Sherrod, eds. Pp. 207-235. Chicago: Aldine. Draper, Patricia, and Nancy Howell

1998 Some Demographic Correlates of Sedentary Status: Ju/'hoansi in the 1960s. Paper presented at the annual meeting of the American Anthropological Association, Philadelphia. Draper, Patricia, and Marian Kranichfeld

1990 Coming in from the Bush: Settled Life by the !Kung and Their Accommodation to Bantu Neighbors. Human Ecology 18:363-384. Duby, Georges

1978 Medieval Marriage: Two Models from 12th Century France. Baltimore: Johns Hopkins University Press.

Dunn, F. L.

1968 Epidemiological factors: health and disease in hunter-gatherers. In Man the Hunter, I. DeVore and R. B. Lee, eds. Pp. 221-229. Chicago: Aldine.

Dyson-Hudson, Rada, and Dominique Meekers

1998 Children of the Dancing Ground, Children of the House: Costs and Benefits of Marriage Rules (South Turkana, Kenya). Journal of Anthropological Research 54:19-47.

Easterlin, R. A., G. Alter, and G. A. Condran

1978 Farms and Farm Families in New and Old Areas: The Northern States in 1860. In Family and Population in Nineteenth-Century America, T. K. Hareven and M. K. Vinovskis, eds. Princeton: Princeton University Press.

Ernst, C., and J. Angst

1983 Birth Order: Its Influence on Personality. New York: Springer-Verlag.

Exner, J., and B. Sutton-Smith

1970 Birth Order and Hierarchical vs. Innovative Role Requirements. Journal of Personality 38:581-587.

Fernandes-Costa, R., J. Marshall, C. Ritchie, et al.

1984 Transition from a Hunter-Gatherer to a Settled Lifestyle in the !Kung San: Effect on Iron, Folate, and Vitamin B12 Nutrition. American Journal of Clinical Nutrition 40:1295-1303.

Galton, F.

1874 English Men of Science: Their Nature and Nurture. London: MacMillan. Gaulin, S. J. C., and C. J. Robbins

1991 Trivers-Willard Effect in Contemporary North American Society. American Journal of Physical Anthropology 85:61-70.

Greenhalgh, Susan, ed.

1995 Situating Fertility: Anthropology and Demographic Inquiry. Cambridge: Cambridge University Press.

Hagestad, Gunhild

1990 Social Perspectives on the Life Course. In Handbook of Aging and the Social Sciences, R. Binstock and L. George, eds. Pp. 151-168. New York: Academic Press.

Hames, Raymond

1979 Relatedness and Interactions among the Ye'kwana: A Preliminary Analysis. In Evolutionary Biology and Human Social Behavior: An Anthropological Perspective, N. A. Chagnon and W. Irons, eds. Pp. 238-249. North Scituate, Massachusetts: Duxbury Press. 
1987 Relatedness and Garden Labor Exchange among the Ye'Kwana. Ethology and Sociobiology 8:354-392.

1988 The Allocation of Parental Care among the Ye'kwana. In Human Reproductive Behavior: A Darwinian Perspective, L. Betzig, M. Borgerhoff Mulder, and P. Turke, eds. Pp. 237-252. Cambridge: Cambridge University Press.

Hammel, Gene

1987 Research in Population and Culture: An Evolutionary Framework. Current Anthropology 28:141-160.

Hansen, J. D. L., et al.

1993 Hunter-Gatherer to Pastoral Way of Life: Effects of the Transition on Health, Growth, and Nutritional Status. Southern African Journal of Science 89:559-564.

Hareven, Tamara

1986 Historical Changes in the Social Construction of the Life Course. Human Development 29(3):171-180.

Harpending, Henry, and Patricia Draper

1990 Estimating Parity of Parents: Application to the History of Infertility among the !Kung of Southern Africa. Human Biology 62:195-203.

Hausman, Alice J., and Edwin N. Wilmsen

1985 Economic Change and Secular Trends in the Growth of San Children. Human Biology 57:563-571.

Hawkes, Kristen, James F. O'Connell, and Nicholas G. Blurton Jones

1989 Hardworking Hadza Grandmothers. In Comparative Socioecology: The Behavioural Ecology of Humans and Other Mammals, V. Standen and R. A. Foley, eds. Pp. 341-366. Oxford: Blackwell Scientific.

1997 Hadza Women's Time Allocation, Offspring Provisioning, and the Evolution of Long Postmenopausal Life Spans. Current Anthropology 38:551-577.

Heath, Kathleen

1996 Life History Strategies and the Reproductive Payoffs of Kin Propinquity. Ph.D. Dissertation, Department of Anthropology, University of Utah, Salt Lake City.

Hewlett, B. S.

1988 Sexual Selection and Paternal Investment among Aka Pygmies. In Human Reproductive Behavior: A Darwinian Perspective, L. Betzig, M. Borgerhoff Mulder, and P. Turke, eds. Pp. 263-276. Cambridge: Cambridge University Press.

Hill, Kim

1993 Life History Theory and Evolutionary Anthropology. Evolutionary Anthropology 2:78-88.

Hill, K., and A. Magdalena Hurtado

1996 Ache Life History: The Ecology and Demography of a foraging People. New York: Aldine de Gruyter.

1997a The Evolution of Premature Reproductive Senescence and Menopause in Human Females: An Evaluation of the "Grandmother Hypothesis." In Human Nature: A Critical Reader, L. Betzig, ed. Pp. 118-139. New York: Oxford University Press.

1997b How Much Does Grandma Help? In Human Nature: A Critical Reader, L. Betzig, ed. Pp. 140-143. New York: Oxford University Press. 
Hitchcock, Robert K.

1988 Settlement, Seasonality, and Subsistence Stress among the Tyua of Northern Botswana. In Coping with Seasonal Constraints, R. Huss-Ashmore, ed. Pp. 64-85. Philadelphia: Museum of Applied Science Center for Archaeology.

Hitchcock, Robert K., James I. Ebert, and Richard G. Morgan

1989 Drought, Drought Relief, and Dependency among the Basarwa of Botswana. In African Food Systems in Crisis, Part One: Microperspectives, R. Huss-Ashmore and S. H. Katz, eds. Pp. 303-336. New York: Gordon and Breach.

Horton, Susan

1986 Child Nutrition and Family Size in the Philippines. Journal of Development Economics 27:55-76. 1988 Birth Order and Child Nutritional Status: Evidence from the Philippines. Economic Development and Cultural Change 36:341-354.

Howell, Nancy

1979 Demography of the Dobe!Kung. New York: Academic Press.

Hrdy, Sarah Blaffer

1992 Fitness Tradeoffs in the History and Evolution of Delegated Mothering with Special Reference to Wet-Nursing, Abandonment, and Infanticide. Ethology and Sociobiology 13:409-442.

Hrdy, Sarah Blaffer, and Debra S. Judge

1993 Darwin and the Puzzle of Primogeniture: An Essay on Biases in Parental Investment after Death. Human Nature 4:1-45.

Jacobs, B. S., and H. A. Moss

1976 Birth Order and Sex of Sibling as Determinants of Mother-Infant Interaction. Child Development 47:101-136.

Jefferson, T, J. H. Herbst, and R. R. McCrae

1998 Associations between Birth Order and Personality Traits: Evidence from Self-reports and Observer Ratings. Journal of Research in Personality 32:498-509.

Kaplan, H.

1996 A Theory of Fertility and Parental Investment in Traditional and Modern Human Societies. Yearbook of Physical Anthropology 39:91-135.

Kent, S., and R. B. Lee

1992 A Hematological Study of !Kung Kalahari Foragers: An Eighteen-Year Comparison. In Diet, Demography, and Disease: Changing Perspectives on Anemia, P. Stuart-Macadam and S. Kent, eds. Pp. 193-199. New York: Aldine de Gruyter.

Kertzer, David, ed.

1986 A Life Course Approach to Coresidence, Vol. II. Greenwich, Connecticut: JAI Press.

Kitcher, Philip

1985 Vaulting Ambition: Sociobiology and the Quest for Human Nature. Cambridge: MIT Press.

Koch, Helen

1955 Some Personality Correlates of Sex, Sibling Position, and Sex of Sibling among Five and Six Year Old Children. Genetic Psychological Monographs 52:3-50. 
Konner, Melvin J.

1972 Aspects of the Developmental Ethology of a Foraging People. In Ethological Studies of Child Behavior, N. G. Blurton Jones, ed. Pp. 285-304. Cambridge: Cambridge University Press.

1976 Maternal Care, Infant Behavior and Development among the !Kung. In Kalahari Hunter Gatherers: Studies of the !Kung San and Their Neighbors, R. B. Lee and I. DeVore, eds. Pp. 218-245. Cambridge: Harvard Uni-

Lee, R. B. versity Press.

1979 The !Kung San: Men, Women and Work. Cambridge: Cambridge University Press.

Low, B. S.

1990 Occupational Status, Land Ownership, and Reproductive Behavior in 19th Century Sweden: Tuna Parish. American Anthropologist 92:115-126.

1991 Reproductive Life in Nineteenth Century Sweden: An Evolutionary Perspective on Demographic Phenomena. Ethology and Sociobiology 12:411448. 1993 Ecological Demography: A Synthetic Focus in Evolutionary Anthropology. Evolutionary Anthropology 1:177-187.

Mace, Ruth

1996 Biased Parental Investment and Reproductive Success in Gabbra Pastoralists. Behavioral Ecology and Sociobiology 38:75-81.

Majoribanks, K.

1988 Sibling, Family Environment and Ability Correlates of Adolescents' Aspirations: Ethnic Group Differences. Journal of Biosocial Science 20:203-209.

1989 Ethnicity, Sibling and Family Correlates of Young Adults' Status AttainMarshall, Lorna ment: A Follow-up Study. Social Biology 36:23-31.

1960 !Kung Bushmen Bands. Africa 30:325-355.

1961 Sharing, Talking, and Giving: Relief of Social Tensions among the !Kung Bushmen. Africa 31:231-249.

1965 The !Kung Bushmen of the Kalahari Desert. In Peoples of Africa, J. L. Gibbs, ed. Pp. 241-278. New York: Holt, Rinehart and Winston.

1976 The !Kung of Nyae Nyae. Cambridge: Harvard University Press.

Miller, J. E., and R. Huss-Ashmore

1989 Do Reproductive Patterns Affect Maternal Nutritional Status? An Analysis of Maternal Depletion in Lesotho. American Journal of Human Biology 1:409-419.

Miller, N., and G. Maruyama

1976 Ordinal Position and Peer Popularity. Journal of Personality and Social Psychology 33:123-131.

Nurse, George T., and Trefor Jenkins

1977 Health and the Hunter-Gatherer: Bio-medical Studies on the Hunting and Gathering Populations of Southern Africa, Vol. 8. Basel: S. Karger.

Pennington, R., and H. Harpending

1988 Fitness and Fertility among Kalahari !Kung. American Journal of Physical Anthropology 77:303-319.

Perusse, Daniel

1993 Cultural and Reproductive Success in Industrial Societies: Testing the Re- 
lationship at the Proximate and Ultimate Levels. Behavioral and Brain Sciences 16:267-322.

Powell, Brian, and Lala Carr Steelman

1993 The Educational Benefits of Being Spaced Out: Sibship Density and Educational Progress. American Sociological Review 58:367-381.

Rosenblatt, Paul C., and Elizabeth L. Skoogberg

1974 Birth Order in Cross-Cultural Perspective. Developmental Psychology 10:48-54.

Roth, Eric Abella

1995 A Reexamination of Rendille Population Regulation. American Anthropologist 95:597-611.

Sahlins, M.

1965 On the Sociology of Primitive Exchange. In The Relevance of Models in Social Anthropology, M. Banton, ed. Pp. 139-236. London: Tavistock.

Salmon, Catherine A., and Martin Daly

1998 Birth Order and Familial Sentiment: Middleborns Are Different. Evolution and Human Behavior 19:299-312.

Schacter, S.

1963 Birth Order, Eminence and Higher Education. American Sociological Review 28:757-767.

Scheper-Hughes, Nancy

1992 Death Without Weeping: The Violence of Everyday Life in Brazil. Berkeley: University of California Press.

Scheper-Hughes, Nancy, ed.

1987 Child Survival: Anthropological Perspectives on the Treatment and Maltreatment of Children. Dordrecht: Reidel.

Schooler, C.

1972 Birth Order Effects: Not Here, Not Now. Psychological Bulletin 78:161-175.

Scrimshaw, Susan

1984 Infanticide in Human Populations: Societal and Individual Concerns. In Infanticide: Comparative and Evolutionary Perspectives, G. Hausfater and S. B. Hrdy, eds. Pp. 439-462. New York: Aldine.

Shavit, Yossi, and Jennifer L. Pierce

1991 Sibship Size and Educational Attainment in Nuclear and Extended Families. American Sociological Review 56:321-330. Smith, M. S., B. J. Kish, and C. B. Crawford

1987 Inheritance of Wealth as Human Kin Investment. Ethology and Sociobiology 8:171-182.

Steelman, Lala Carr, and Brian Powell

1985 The Social and Economic Consequences of Birth Order: Real, Artifactual or Both? Journal of Marriage and the Family 47:117-124.

Sulloway, Frank J.

1996 Born to Rebel: Birth Order, Family Dynamics, and Creative Lives. New York: Vintage Books.

Taubman, P., and J. R. Behrman

1986 Effect of Number and Position of Siblings on Child and Adult Outcomes. Social Biology 33:22-34.

Trivers, Robert L.

1974 Parent-Offspring Conflict. American Zoologist 14:249-264. 
Trivers, R., and D. Willard

1973 Natural Selection of Parental Ability to Vary the Sex Ratio of Offspring. Science 179:90-92.

Turke, Paul

1988 Helpers at the Nest: Child care Networks on Ifaluk. In Human Reproductive Behavior: A Darwinian Perspective, L. Betzig, M. Borgerhoff Mulder, and P. Turke, eds. Pp. 173-188. Cambridge: Cambridge University Press.

1997 Hypothesis: Menopause Discourages Infanticide and Encourages Continued Investment by Agnates. Evolution and Human Behavior 18:3-13.

Vining, D. R.

1986 Social versus Reproductive Success: The Central Theoretical Problem of Human Sociobiology. Behavioral and Brain Sciences 9:167-216.

Voland, E.

1984 Human Sex-Ratio Manipulation: Historical Data from a German Parish. Journal of Human Evolution 13:99-107.

1990 Differential Reproductive Success within the Krummhom Population (Germany, 18th and 19th Centuries). Behavioral Ecology and Sociobiology 26:65-72.

1998 Evolutionary Ecology of Human Reproduction. Annual Review of Anthro-

Walton, J. N. pology 27:347-374.

1997 Birth Order, Sibship Size and Status in Modern Canada. Human Nature 8:205-230.

Wehmeyer, A. S., R. Lee, and M. Whiting

1969 Nutrient Composition and Dietary Importance of Some Vegetable Foods Eaten by the !Kung Bushmen. South African Medical Journal 43:1528-1540.

Whiting, J. W. M.

1960 Contributions of Anthropology to the Methods of Studying Child Rearing. In Handbook of Research Methods in Childhood Development, P. H.

Wiessner, Polly Mussen, ed. Pp. 918-944. New York: John Wiley.

1982 Risk, Reciprocity and Social Influences on !Kung San Economics. In Politics and History in Band Societies, E. Leacock and R. Lee, eds. Pp. 61-84. Cambridge: Cambridge University Press.

1997 Seeking Guidelines through an Evolutionary Approach: Style Revisited among the !Kung San (Ju/'hoansi) of the 1990s. In Rediscovering Darwin: Evolutionary Theory and Archaeological Explanation, M. Barton and G. Clark, eds. Pp. 157-176. Washington, D. C.: Archaeological Publications of the American Anthropological Association Monograph Series.

Wilmsen, E. T.

1982 Studies in Diet, Nutrition, and Fertility among a Group of Kalahari Bushmen in Botswana. Anthropology of Food. Social Science Information 21:95-125.

Wood, James W.

1994 Dynamics of Human Reproduction: Biology, Biometry, Demography. Hawthorne, New York: Aldine de Gruyter.

Worthman, C. M.

1996 Survivorship, Selection and Socialization: Biosocial Determinants of Sex Ratios. In Long-Term Consequences of Early Environments, S. J. Uli- 
jaszek and C. J. K. Henry, eds. Pp. 45-68. Cambridge: Cambridge University Press.

Yellen, John E.

1977 Long-Term Hunter-Gatherer Adaptations to Desert Environments: A Biogeographical Perspective. World Archaeology 8:262-274.

1984 The Integration of Herding into Prehistoric Hunting and Gathering Economies. In Frontiers: Southern African Archaeology Today, M. Hall, G. Avery, D. M. Avery, M. L. Wilson, and A. J. B. Humphreys, eds. Pp. 53-64. BAR International Series 207. Oxford: British Archaeological Reports.

Zajonc, R. B., and J. Bargh

1980a Birth Order, Family Size and Decline in SAT Scores. American Psychologist 35:662-668. 1980b The Confluence Model: Parameter Estimation for Six Divergent Data Sets on Family Factors and Intelligence. Intelligence 4:349-361.

Zajonc, R. B., and G. B. Markus

1975 Birth Order and Intellectual Development. Psychological Review 82:74-88.

Zajonc, R. B., H. Markus, and G. B. Markus

1979 The Birth Order Puzzle. Journal of Personality and Social Psychology 37:1325-1341. 